\title{
The Effect of the Child-Parent Relation Therapy Program on the Parenting Stress and Parenting Efficacy of Mothers of the Multi- Cultural Families
}

\author{
*Minkyeong Kim, Professor, Department of Child Welfare, Namseoul University, 91 Daehakro \\ Sunghwaneup Seobukgu Cheonan City, 31020, South Korea, ilu35@hanmail.net
}

\begin{abstract}
Multicultural mothers have difficulty in helping children study and also playing with them without knowing and what and how to do. The object of this study was to identify the effects of parenting sense of competence of International married women. SPSS 23.0 was used for data analysis to verify the effects of the training program. Among statistical methods, for homogeneity, the Mann-Whitney U Test was used and for difference of pretest and post-test, the Wilcoxon Singed-Rank Test was conducted. Parenting stress was measured by Abidin's parenting stress Index. Parenting competence was measured by Shin's Parenting Sense of Competence(PSOC). The results of this study were as follows; A play-based self-expression training program is effective in improving the caring efficacy of International married women. There were statistically significant differences shown in 3 sub-factors of the feeling of rearing efficacy, including the feeling of the parental efficacy, the feeling of the insecurity of the parent, and the role and the interest of the parent. This study has a significance in terms that it proved the effects of the child-parent relation therapy program, and the effects were confirmed by an experimental study.

Keywords: Child-Parent Relation Therapy Program, Intermarried women, Multicultural family, Parental Efficacy, Child-Parent Play

Received: 09.12.2020 $\quad$ Accepted: 10.01.2021 $\quad$ Published: 02.02.2021
\end{abstract}

\section{INTRODUCTION}

Many mothers of multicultural families struggle with the stress about rearing their children due to cultural differences and language problems, which often come with the haste in getting married through matchmaking agents and having a baby[1]. They had to perform the maternal role well before they got adjusted and prepared, which would inevitably increase their psychological and mental stress about the maternal role and worsen their personal difficulties[2].

Multicultural mothers have difficulty in helping children study and also playing with them without knowing and what and how to do. They are also worried that their low proficiency in the Korean language and consequent insufficient communication would perhaps lead to a negative influence on the cognitive development of their children[3]. It was also reported that these mothers feel that they could not give enough help to their children due to poor communication and cultural differences. They were worried that they would look incompetent to their children and their lowered parenting efficacy would lead to increased rearing stress and anxiety over the relationship with their children[4].

As discussed above, these mothers have to face a unique challenge of rearing children in a society totally different from their homeland. However, it is hopeful that their rearing stress can be effectively overcome by possessing balanced rearing efficacy through effective combination and application of their unique cultural asset, knowledge, technology with proper skills of rearing and educating children. It was already reported that multicultural mothers with higher rearing efficacy succeeded in dealing with rearing stress more effectively[5].

Child-Parent Relationship Therapy(CPRT) developed by Bernard Guerney in 1964 can enhance the effect of therapy by letting parents participate in the therapy together with their children having psychological and/or emotional difficulties[6]. These programs are basically children-oriented and emphasize that parents should be able to use the principles and skills of play therapy in their real lives. Through such training, parents are expected to be more sensitive to children and able to create unjudgemental, receptive and considerate environments. As a consequence, it would enhance the childparent relationship as well as reduce children's problematic behavior[7].

Parents attend particular lectures and participate in play sessions with children, which would be videotaped for direct and immediate coaching from expert trainers. These sessions are very effective for multicultural mothers, since the program would help parents learn how to interact with children, how to improve the relationship with them, and also how to discipline them. 
Regarding the Child-Parent Relationship Therapy (CPRT) training program that had been used in this research, the manual of the 10 session model that had been developed by [6] for the children who possess the problem of the adaptation who were between 3 years old and 10 years old into the Child-Parent Relationship Therapy (CPRT) program by [8,9] had been used as the basis.

The purpose of research reveals the effects of the Child-Parent Relationship Therapy (CPRT) program on the rearing stress and the feeling of rearing efficacy of the mothers of the multi-cultural families. For the purpose of the research, regarding the selection of the subjects of the research, after informing the effects and the purpose of the child-parent relationship therapy training program. The research had been carried out with the mothers of the multi-cultural families who have the intention to participate as the subjects. And the research had been organized with the 10 persons in the experimental group and the 10 persons in the control group.

\section{Methods}

\subsection{Subjects}

This study was conducted in first-, second-, and third-graders from multicultural families at $\mathrm{S}$ Multicultural Family Support Center in Chungnam Province who intended to participate in child-parents relation therapy. A total of 8 children formed the experimental and the control group.

This study was conducted in first-, second-, and third-graders from multicultural families at S Multicultural Family Support Center in Chungnam Province who intended to participate in child-parent relationship therapy. A total of 8 children formed the experimental group and formed the control group.

The demographic characteristics of the 20 subjects (10 experimental and 10 control) were as follows. All the subjects were originally from Southeast Asia: 5 from Cambodia, 3 from Vietnam and 2 from Thailand for the experimental group, and 4 from Cambodia, 3 from Vietnam and 3 from Thailand for the control group. As for their ages, a great majority of them were in the 30's: both groups had 9 in the 30's and 1 in the 40's.

\subsection{Tools}

\subsubsection{Parenting stress}

The subjects' rearing stress was measured by Abidin's Parenting Stress Index/Short Form(PSI/SF) [10]. The subjects were asked to answer to the questionnaire consisting of 20 questions belonging to three categories: children's disposition, relationship with children, and learning expectation. The items had a 5-point scale. The greater score meant the greater parenting stress. The index of each category was as follows: .942 for children's disposition .711 for the relationship with children, and .781 for the learning expectation. At the post-test, in turn, the reliability of the whole scale was .979. Cronbach's $\alpha$ for each category was found at .989 for children's disposition, .920 for the relationship with children, and .949 for learning expectation, respectively.

\subsubsection{Parenting efficacy}

Parenting Sense of Competence(PSOC) of scale used [11]. This tool consisted of feeling of rearing efficacy, including the feeling of the parental efficacy, the feeling of the insecurity of the parent, and the role and the interest of the parent. Cronbach's $\alpha$ was .89 for overall items at the pre-test: .863 for parent efficacy, .725 for parents' anxiety, .740 for parental role/interest. The overall reliability at the post-test, in contrast, was .890: .938 for parent efficacy, .974 for parents' anxiety and .813 for parental role/interest.

\subsection{Program reconstitution for child-parent relation therapy}

The content of program consists of 10 sessions: to introduce program and name, Tracking, Do/Do not, defining limitation, general problems, self-respect, encouragement, choice, rules.

\subsection{Data analysis}

SPSS 23.0 was used for analysis to verify the effects of the program. Among statistical methods, for homogeneity, the Mann-Whitney U Test was used and for difference of pretest and post-test, the Wilcoxon Singed-Rank Test was conducted.

\section{Results and Discussion}

\subsection{Homogeneity}

Wilcoxon signed rank test is more powerful than sign test when paired two group's difference verification. 


$$
\begin{array}{r}
\mathbf{Z}=\frac{\mathbf{T}-\frac{\mathbf{N}(\mathbf{N}+\mathbf{1})}{4}}{\sqrt{\frac{\mathbf{N}(\mathbf{N}+\mathbf{1})(\mathbf{2 N}+1)}{\mathbf{N}-1}}} \\
\text { Mann-Whitney } \mathrm{U} \text { test is used for homogeneity of test. } \\
\mathrm{U}_{1}+\mathrm{U}_{2}=\mathrm{n}_{1} \mathrm{n}_{2}+\mathrm{n}_{1} \mathrm{n}_{2}+\frac{\mathrm{n}_{1}\left(\mathrm{n}_{1}+1\right)}{2}+\frac{\mathrm{n}_{2}\left(\mathrm{n}_{2}+1\right)}{2}-\left(\Sigma^{\mathrm{R}_{1}}+\Sigma^{\mathrm{R} 2}\right) \\
\mathrm{n}_{1} \mathrm{n}_{2}+\frac{\mathrm{n}_{1}\left(\mathrm{n}_{1}+1\right)}{2}+\frac{\mathrm{n}_{2}\left(\mathrm{n}_{2}+1\right)}{2}=\Sigma^{\mathrm{R}_{1}}+\Sigma^{\mathrm{R} 2}=\mathrm{T} \\
\text { so, } \mathrm{U}_{1}+\mathrm{U}_{2}=\mathrm{n}_{1} \mathrm{n}_{2}
\end{array}
$$

\begin{tabular}{|c|c|c|c|c|c|c|c|}
\hline \multirow{2}{*}{ Parenting stress } & Experimental & 10 & 12.10 & 121.00 & \multirow{2}{*}{34.000} & \multirow{2}{*}{-1.222} & \multirow{2}{*}{.222} \\
\hline & Control & 10 & 8.90 & 89.00 & & & \\
\hline \multirow{2}{*}{$\begin{array}{l}\text { Parenting } \\
\text { efficacy }\end{array}$} & Experimental & 10 & 9.85 & 98.50 & \multirow{2}{*}{43.500} & \multirow{2}{*}{-.496} & \multirow{2}{*}{.620} \\
\hline & Control & 10 & 11.15 & 111.50 & & & \\
\hline
\end{tabular}

Table 1. Homogeneity of parenting stress and parenting efficacy

$\begin{array}{llllll}\text { Group } & \mathrm{N} & \begin{array}{l}\text { Mean } \\ \text { order }\end{array} & \begin{array}{l}\text { Sum } \\ \text { Order }\end{array} & \text { of Mann- } & \text { Whitney U }\end{array} \quad$ z

The analysis of the homogeneity of the two groups in their ability to control parenting stress and parenting efficacy found that the mean rank of the experimental group was 12.10, 9.85 in contrast to 8.80, 11.15 of the control group as shown in Table 1. Thus, the difference was not statistically significant, verifying the homogeneity of the two groups in their control parenting stress and parenting efficacy before the child-parent relation therapy program was conducted.

\subsection{Difference of parenting stress}

Difference of parenting stress changing multicultural mother showed Table 2 was significantly different positive rank of parenting stress was 8 . Negative rank of parenting stress was 0 . Therefore it means that positive change mother was much better than negative changing multicultural mother. The pre-test and post-test was performed to examine the effect of CPRT program on the parenting stress of multicultural mothers, who belonged to either an experimental group or a control group.

The Wilcoxon signed rank test conducted to the experimental group to examine differences between the pre-test and the post-test revealed that all the 10 samples marked a negative(minus) value with none having a positive(plus) value. The mean rank of the cases showing a greater result at the post-test was 5.50 and that

\begin{tabular}{|c|c|c|c|c|}
\hline group & & $\mathrm{N}$ & $\begin{array}{l}\text { Mean } \\
\text { order }\end{array}$ & $\begin{array}{l}\text { Sum of } \\
\text { Order }\end{array}$ \\
\hline \multirow{2}{*}{$\begin{array}{l}\text { Experimental: } \\
\text { parenting stress }\end{array}$} & $\begin{array}{l}\text { negative } \\
\text { rank }^{\mathrm{a}}\end{array}$ & 10 & 5.50 & \multirow{2}{*}{$-2.81^{* *}$} \\
\hline & $\begin{array}{l}\text { positive } \\
\text { rank }^{b}\end{array}$ & 0 & .00 & \\
\hline
\end{tabular}
showing a lesser result was 0.00 , which clearly indicates that the differences between the pre- and post-tests were statistically significant at the level of $\mathrm{p}<.01$. Therefore, it might be concluded that the CPRT program helped reduce rearing stress of the subjects.

Table 2. Difference of parenting stress change before and after program intervention 


\begin{tabular}{|c|c|c|c|c|c|}
\hline & $\mathrm{tie}^{\mathrm{c}}$ & 0 & & & \\
\hline & total & 10 & & & \\
\hline \multirow{4}{*}{$\begin{array}{l}\text { Control: } \\
\text { parenting stress }\end{array}$} & $\begin{array}{l}\text { negative } \\
\text { rank }^{\mathrm{a}}\end{array}$ & 0 & 1.50 & 3.00 & \multirow{4}{*}{-1.32} \\
\hline & $\begin{array}{l}\text { positive } \\
\text { rank }^{\mathrm{b}}\end{array}$ & 2 & .00 & .00 & \\
\hline & $\mathrm{tie}^{\mathrm{c}}$ & 8 & & & \\
\hline & total & 10 & & & \\
\hline
\end{tabular}

${ }^{* *} p<.01 \quad$ c: post test $=$ pre test b: post test $>$ pre test a: post test $<$ pre test

\subsection{Difference of parenting efficacy}

Difference of parenting sense of efficacy changing multicultural mother showed Table 3 was significantly different positive rank of parenting sense of efficacy was 8. negative rank of parenting sense of efficacy was 0 . Therefore, it means that positive change mother was much better than negative changing multicultural mother. The pre-test and post-test was performed to examine the effect program on the parenting efficacy of multicultural mothers, who belonged to either an experimental group or a control group.

It was found that no case marked a negative value in rearing efficacy and that all the 10 cases showed a plus value. As a consequence, the mean rank of the cases with a lesser result at the posttest was 0.00 and that of the cases with a greater result at the posttest was 5.50. The difference between the two tests in rearing efficacy was statistically significant at the level of $\mathrm{p}<.01$. It would lead us to conclude that the CPRT therapy program exerted a positive effect on their rearing efficacy.

Table 3. Difference of parenting efficacy change of program intervention

\begin{tabular}{|c|c|c|c|c|c|}
\hline group & & $\mathrm{N}$ & $\begin{array}{l}\text { Mean } \\
\text { order }\end{array}$ & $\begin{array}{l}\text { Sum } \\
\text { Order }\end{array}$ & \\
\hline \multirow{4}{*}{$\begin{array}{l}\text { Experimental: } \\
\text { parenting stress }\end{array}$} & $\begin{array}{l}\text { negative } \\
\text { rank }^{\mathrm{a}}\end{array}$ & 0 & 0 & 0 & \multirow{4}{*}{$-3.05^{* *}$} \\
\hline & $\begin{array}{l}\text { positive } \\
\text { rank }^{b}\end{array}$ & 8 & 5.5 & 55.5 & \\
\hline & $\mathrm{tie}^{\mathrm{c}}$ & 0 & & & \\
\hline & total & 8 & & & \\
\hline \multirow{4}{*}{$\begin{array}{l}\text { Control: } \\
\text { parenting stress }\end{array}$} & $\begin{array}{l}\text { negative } \\
\text { rank }^{a}\end{array}$ & 1 & 1.50 & 3.50 & \multirow{4}{*}{-.23} \\
\hline & $\begin{array}{l}\text { positive } \\
\text { rank }^{b}\end{array}$ & 7 & .00 & .00 & \\
\hline & $\mathrm{tie}^{\mathrm{c}}$ & 0 & & & \\
\hline & total & 8 & & & \\
\hline
\end{tabular}

${ }^{* *} p<.01 \quad$ c: post test $=$ pre test b: post test $>$ pre test a: post test $<$ pre test 


\section{Conclusion}

According to the reports from the participating mothers, they would feel stress about communication and proper responses due to their children's increasing language proficiency. In fact, at the earlier stages of the therapy program, these mothers found it difficult to understand their children's language, while the children tried to communicate with mothers and show their desires. As the sessions proceed, the mothers tried to use the learned skills of showing empathy with the children's emotions and repeat after their behavior and facial expressions. The research subjects' increasing reflective responses to their children and adaptation to such communicative relationship did help reduce their rearing stress that was greatly attributable to difficulty in communication and language.

Second, it was also found that the CPRT program helped enhance the multicultural mothers' rearing efficacy. According to the subjects' reports, they felt it very awkward at the beginning stages to participate in particular plays with children. However, they mentioned that the playing sessions greatly helped them recognize and notice their children's emotions and thoughts, and, as a consequence, have a more intimate relationship.

It might be safe to conclude that learning and applying the techniques and skills of emphatic listening was helpful and effective. Such skills would help communicate with children in a proper direction. The multicultural mothers without enough linguistic proficiency could still have effective communication by appealing to a set of nonlinguistic standards: they could show empathy by recognizing their facial expressions and also respond by imitating children's behavior. Such skills do not necessarily require language proficiency but still can help reduce rearing stress.

In sum, the present research found that the CPRT program was significantly effective in reducing multicultural mothers' rearing stress and enhancing their rearing efficacy. Further studies are expected to be applied to other mothers with various backgrounds and produce similar results.

\section{Acknowledgment}

Funding for this paper was provided by Namseoul University.

\section{References}

[1] Kang, S.J and S. M. Son. (2011) A Case Study on the Marital Satisfaction and Child-Rearing Perception of Four International Marriage Migrant Women with Infants. Journal of Korea Open Association for Early Childhood Education, 16(6), 161-188.

[2] Sigel, I.E and Ann V. McGillicuddy-DL. (2002) Parent. Beliefs are cognitions: The dynamic belief systems model. In M. H. Bornstein (Ed.), Handbook of parenting(2nd.), Mahwah, NJ: Erlbaum, 485-508.

[3] Park, J. J. (2015) The Effect of Multicultural Family's Functions on the Social Competence of Multicultural Children -Focusing on the Mediating Effect of Multicultural Family Mothers' Parental Efficacy. The Journal of the Korea Contents Association, 15(6), 247-258.

[4] Park, R.G. (2008) Yoon JY. Development and the Effects of Group Theraplay for Mother-Child of Multicultural Family. Korean Journal of Child Psychotherapy, 3(2), 61-82.

[5] Lee, J.Y. (2012) Research on the Influence of Mothers' Enculturation Stress and Parental Stress on Children's Maladjustment in Multicultural Families - Focusing on a Control Effect of Family Functions. Korean Journal of Family Welfare, 17(2), 105-125.

[6] Guerney, B.J. (1964). Filial therapy; Description and rationale. Journal of Consulting Psychology, 28, 303-310.

[7] Lee, R.H and H. L. Jang. (2019) A Case Study on the Marital Satisfaction and Child-Rearing Perception of Four International Marriage Migrant Women with Infants. Korean Journal of Child Welfare, 68(1), 65-95.

[8] Landreth, G. L., S. Bratton, T. Kellam and S. Blackard. (2006) Child parent relationship therapy (CPRT). Treatment manual: A 10-Session filial therapy model for training parent. NY: Routledge, 11-185.

[9] Choi, M.K., N.N. Shin,M. J. Kim and H. S. Do. (2013) Child-parent relationship therapy manual-10 sessio n child-parent play therapy model. Seoul: Hakjisa, 20-230.

[10] Abidin, R.R. (1990) Parenting stress index short form, Charlottesville, VA: Pediatric Psychology Press, $35-47$.

[11] Moon, H. J and M. S. Kim. (2005) Relationship between parenting stress and parenting efficacy on parenting behaviors in mother with young children. Family and Environment Research, 43(8), 25-35. 